\title{
A lethal skeletal dysplasia with features of chondrodysplasia punctata and osteogenesis imperfecta: an example of Astley-Kendall dysplasia. Further delineation of a rare genetic disorder
}

Nursel Elçioglu, Christine M Hall

\begin{abstract}
An unusual osteochondrodysplasia presenting with lethal neonatal short limbed dwarfism, defective ossification, and punctate calcification within cartilage is presented. The features resemble four cases previously described with AstleyKendall dysplasia.
\end{abstract}

(F Med Genet 1998;35:505-507)

Keywords: osteochondrodysplasia; short limbed dwarfism; lethal; Astley-Kendall dysplasia

A review of 3500 cases on the Skeletal Dysplasia Registry of the Department of Radiology, Great Ormond Street Hospital for Children NHS Trust identified a fetus with striking radiological features resembling both chondrofecta.

Astley-Kendall dysplasia is characterised radiologically by absent ossification of the cranial vault and multifocal ossification giving a stippled appearance involving the axial skeleton and carpus and tarsus. In addition, the ribs are short and deformed, the vertebral bodies flat, and the long bones short and deformed, with diaphyseal fractures and flared metaphyses.

Greenberg dysplasia (hydrops-ectopic calcification-motheaten skeletal dysplasia, HEM) has a poorly ossified skull vault, a fragmented, "mottled" appearance of the long bones, most pronounced at their ends, but extending to involve the diaphyses. ${ }^{2}$

Dappled diaphyseal dysplasia (DDD) has

Department of

Radiology, Great

Ormond Street

Hospital for Children

NHS Trust, London

WC1N 3JH, UK

N Elçioglu^

C $M$ Hall

Correspondence to: Dr Hall.

$\star$ Present address:

Department of Genetics,

Cerrahpasa Medical School,

Istanbul, Turkey.

Received 5 August 1997

Revised version accepted for publication

3 December 1997

Figure 1 Lateral skull: absent ossification of the vault. dysplasia punctata and osteogenesis imper-

vault is unossified. The long bones are extremely short, deformed, and appear fragmented because of multiple ossification centres. The tubular bones of the hands and feet are unossified. Multicentric ossification is also present in the scapulae, pelvis, and facial bones. The vertebrae are less severely affected. ${ }^{3}$ Both HEM and DDD are severely hydropic. ${ }^{23}$

\section{Case report}

This stillborn female was delivered at 34 weeks' gestation. The Pakistani parents were young and healthy. No malformations or bone diseases were known to be present in the family. Neither necropsy nor histochemical examination of the cartilage was performed and no photographs of the patient were obtained.

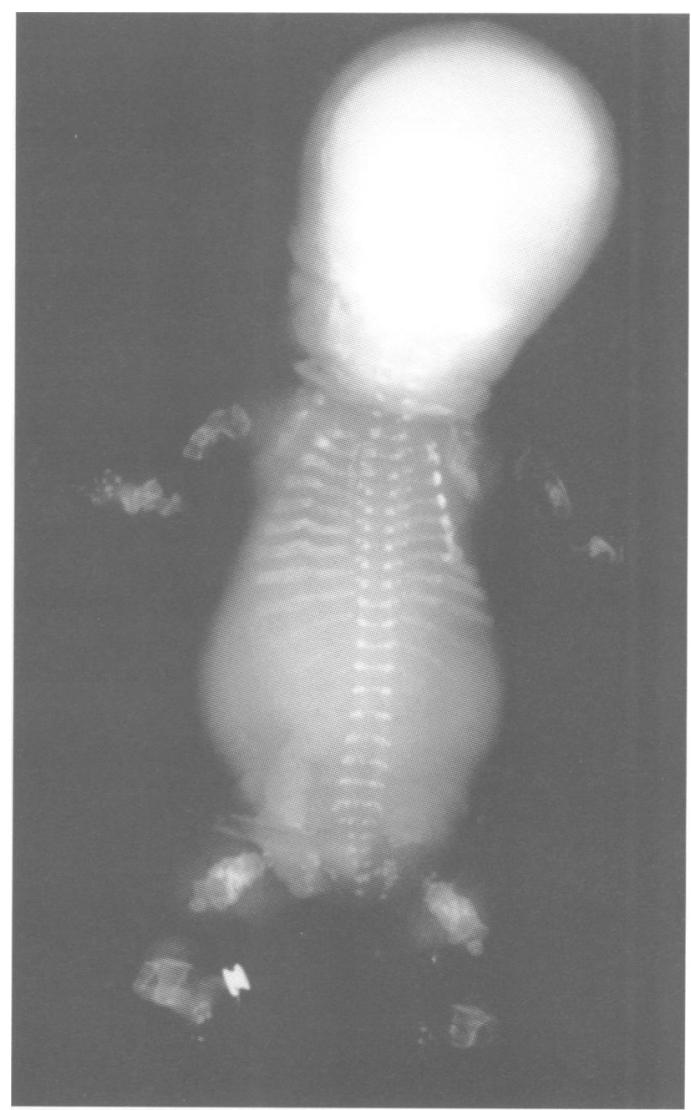

Figure 2 Babygram showing short, deformed limbs, short ribs with transverse defects, and multiple centres of increased bone density in the spine. Wormian bones are visible in the 
Table 1 Comparision of the radiological findings of the present case with the reported Astley-Kendall cases and related conditions

\begin{tabular}{|c|c|c|c|c|c|}
\hline Radiological findings & $\begin{array}{l}\text { Astley- } \\
\text { Kendall }\end{array}$ & $\begin{array}{l}\text { Nairn-Chapman } \\
\quad \text { (all cases) }\end{array}$ & $\begin{array}{l}\text { Present } \\
\text { case }\end{array}$ & $\begin{array}{l}\text { Dappled } \\
\text { diaphyseal }\end{array}$ & $H E M$ \\
\hline \multicolumn{6}{|l|}{ Skull } \\
\hline Lack of ossification of vault & + & + & + & + & + \\
\hline Normal skull base & + & + & + & - & - \\
\hline \multicolumn{6}{|l|}{ Spine } \\
\hline Multiple dense centres (stippling) & + & + & + & + & + \\
\hline Platyspondyly & + & + & + & + & + \\
\hline \multicolumn{6}{|l|}{ Thorax } \\
\hline Small & + & $++/-$ & + & + & + \\
\hline Transverse translucent rib defects & + & + & + & + & + \\
\hline Ribs deformed (wavy) & + & + & + & - & + \\
\hline Ribs broad & + & $++/-$ & + & - & - \\
\hline \multirow{2}{*}{\multicolumn{6}{|c|}{$\begin{array}{l}\text { Pelvis } \\
\text { Petal }\end{array}$}} \\
\hline & & & & & \\
\hline Crescentic ilia & + & + & + & - & - \\
\hline \multicolumn{6}{|l|}{ Limbs } \\
\hline Short and deformed & + & + & + & + & + \\
\hline Constriction and fracture near midpoint of long bones & + & + & + & - & - \\
\hline Angulated tibia/fibula & + & + & + & - & - \\
\hline Normal sized hands and feet & + & + & + & - & - \\
\hline Stippled carpus/tarsus & + & + & + & + & + \\
\hline Punctate epiphyses & + & $++/-$ & + & + & + \\
\hline Splayed metaphyses & + & + & + & - & + \\
\hline Multiple ossification centres of diaphyses & - & - & - & + & + \\
\hline Severe hydrops & - & - & - & + & + \\
\hline Pattern of inheritance & AR & AR & & AR & AR \\
\hline
\end{tabular}

The postmortem radiographs show short, deformed limbs and a narrow thorax with a moderately protuberant abdomen. In the skull there is very poor ossification of the vault which shows multiple wormian bone formation. The base of the skull and facial bones are well developed (fig 1).

In the spine, multiple areas of stippling are seen in the vertebral bodies in the lower thoracic and lumbar regions and the pedicles and transverse processes thoughout. There is marked platyspondyly and absent ossification of vertebral bodies in most of the thoracic region with only a trace of ossification at the levels of D1 and D2. The thorax is narrow with short, broad, spatulate ribs widened at the anterior ends. The ribs are deformed (wavy)

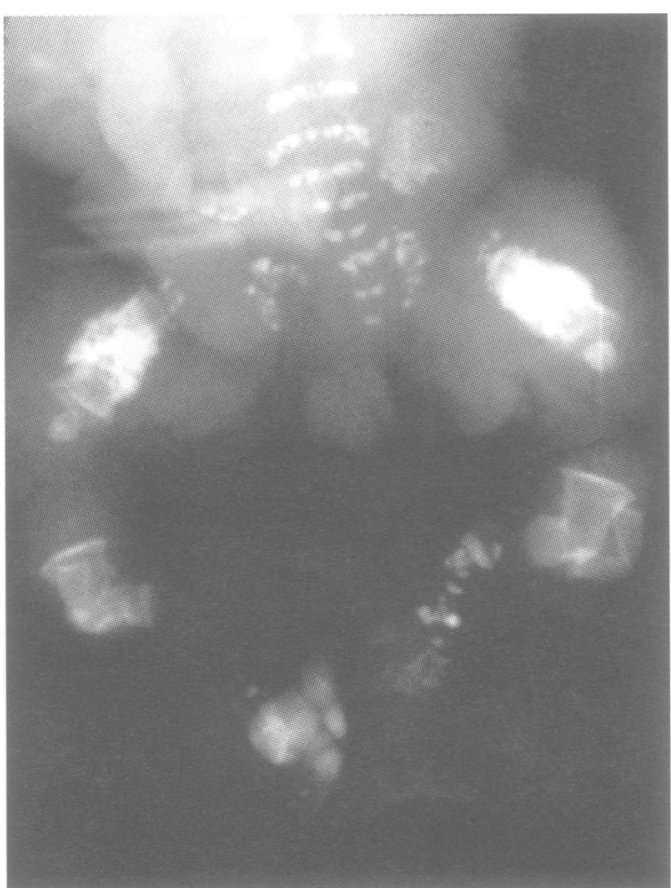

Figure 3 Lower limbs and pelvis showing crescentic ilia stippled ischia, short, deformed femora with wide diaphyses, and angulated tibiaelfibulae. with a few transverse defects suggesting intrauterine fracturing. Punctate calcification is present at the posterior ends of the ribs. The scapulae have an unusual configuration with some deficiency laterally in the infraglenoid position. In the upper limbs, the long bones are short and bowed or angulated. The metaphyses of the proximal humeri are flared. There are radiolucent defects across the mid diaphyses of the humeri with marginal sclerosis and callus indicating healing fractures. Stippling is present in the carpus (fig 2 ).

In the pelvis, the iliac wings are wide, short, and concave inferiorly (crescentic). There is extensive stippling affecting the pubic bones and ischia. Stippling is also present in the upper femoral regions and extensively throughout the tarsus. There is expansion owing to callus with some sclerosis of the diaphyses of both femora and transverse lytic areas representing fracturing. The distal metaphyses and epiphyses are well maintained. The tibiae and fibulae are extremely short and angulated. In the feet, the short tubular bones are well developed with no evidence of deformity (fig 3 ).

\section{Discussion}

This stillborn infant shows a number of features reminiscent of several conditions. In particular, the poor ossification in the cranial vault, transverse defects in the diaphyses of long bones with surrounding callus and sclerosis, angulated tibiae, and broad ribs are features seen in osteogenesis imperfecta. Stippling is a feature of all forms of chondrodysplasia punctata and of other disorders. ${ }^{4}$ In this case the combination of findings is diagnostic of AstleyKendall dysplasia.

Astley and Kendall ${ }^{1}$ described a stillborn infant and Nairn and Chapman ${ }^{5}$ reported another three female sibs from a consanguineous marriage with this condition. However, there have been suggestions published ${ }^{6} 7$ that these sibs had features of DDD and not AstleyKendall dysplasia. It has also been suggested 
that HEM represents a milder form of DDD. ${ }^{67}$ We feel that Astley-Kendall dysplasia is distinct from both DDD and HEM on radiological grounds (table 1).

The chondro-osseous morphology of AstleyKendall dysplasia has been well described. There is dystrophic globular calcification within epiphyses, vacuolated chondrocytes, widened lacunae, and disorganised growth plate with irregular columns, maturational arrest, and thin cortex. Fractures of the diaphyses were present with fibrous tissue proliferation and callus formation. The chondroosseous morphology of HEM is significantly different. $^{2}$

Our case represents the fifth published report of Astley-Kendall dysplasia. To date, all cases of this presumed autosomal recessive disorder, interestingly, have occurred in Asians from the Midlands area of the United Kingdom.

1 Astley R, Kendall AC. A bone dysplasia for diagnosis. Ann Radiol 1980:23:121-3.

2 Greenber CR, Rimoin DI Gruber HE, DeSa DJB, Reed $M$, Lachman RS. A new autosomal recessive lethal chondrodystrophy with congenital hydrops. $\mathrm{Am} \mathrm{f} \mathrm{Med}$ Genet 1988;29:623-32.

3 Carty H, Kozlowski K, Sillence D. Dappled diaphyseal dyplasias. Fortschr Röntgenstr 1989;150:228-9.

4 Poznanski AK. Punctate epiphyses: a radiological sign not disease. Pediatr Radiol 1994;24:418-24.

Nairn ER, Chapman S. A new type of lethal short-limbed dwarfism. Pediatr Radiol 1989;19:253-57.

6 Spranger J, Maroteaux P. The lethal osteochondrodysplasias. Adv Hum Genet 1990;19:1-102.

7 Taybi H, Lachman RS. Radiology of syndromes, metabolic disorders, and skeletal dysplasias. 4th ed. St Louis: Mosby, 1996:838-9. 